\title{
Airline Network in East Asia*
}

\author{
Jun Yeop Lee**, Kisoon Hyun***
}

\begin{abstract}
Using Social Network Analysis (SNA), this paper examines the inter-country airline logistics relationships in East Asia. Based on the flight schedule data, which has been gathered by the authors, the overall features of airline logistics structure and the specific roles of each airport could be more clearly examined.

The main results of this paper are as follows: Beijing has the highest Degree Centrality, but excluding the domestic lines, Incheon has the highest Degree Centrality, which would imply that a relatively high Centrality of logistics for China's airports is due to the greater number of domestic lines. The focal hub status of Incheon airport is also supported by the fact that Incheon contains the highest Betweenness Centrality.

Secondly, evaluated by the types of brokerage role, Incheon has a remarkably strong role as a liaison, which means Incheon airport functions as a transfer hub between two different regions outside of Korea. However, considering only the to/from China airline links, Hong Kong has the highest score as a liaison. These conflicting results imply that as China's airline transportation continuously increases, Hong Kong will become a strong rival to Incheon.

Thirdly, in the analysis of Structural Hole which functions the broker and acts as a hub by linking unconnected airports, Incheon has the highest possibilities as a hub airport. However, only considering to/from China airlines, Hong Kong would dominate Incheon.
\end{abstract}

Key Words: Airline Logistics Network in East Asia, Degree of Centrality, Structural Hole

JEL codes: D85, L98, O18, R41

\footnotetext{
* This work was supported by National Research Foundation of Korea Grant Funded by the Korean Government (MOEHRD)(NRF-2011-413-B00008). Also, this work was supported by Inha University.

** Corresponding author, Professor, Department of International Trade and Regional Studies, Inha University, 100 Inha-ro, Incheon, Korea, E-mail: jylee@inha.ac.kr

${ }^{* * *}$ Research Professor, Jungseok Research Institute of Logistics and Trade, Inha University, 100 Inha-ro, Incheon, Korea, E-mail: kshyun147@gmail.com
} 


\section{Introduction}

Is it possible to examine the airline network in an analytical methodology? Does every airport in East Asia have specific roles in the airline network? In this context, how can we properly analyze the influences of China's economic rise on the airline networks in the Northeast Asia? For Korea, what policies have to be made in response to the airline network expansions in this region? These are the key motivations for this study.

The airline network is a typical example of a spatial network. The nodes are identified as the airports, which are located in a two-dimensional space. The logistics volume between airports can be interpreted as a network density. In this sense, the Social Network Analysis (SNA) can be an effective research methodology.

There have been an increasing number of studies applying SNA to analyze and reveal air transport networks. Through SNA, the overall network structure and characteristics of each node are easily captured. For example, Wang et al.(2011) compared the structure of China's airline network with the U.S. In their study, they found that China's air transport network has a smaller average degree value, a larger average path length and a smaller clustering coefficient than the U.S. airline network. It can be interpreted that the Chinese airline network is a bit immature compared to the U.S airline network. In addition, higher degree cities in China were surrounded by lower-degree neighbors with direct links, and vice versa.

The inter-country airport networks in the Northeast Asian region have increased exponentially during the past decade, which is mainly due to the rapid increase of China's logistics volumes both in air passengers and air freight. Most importantly, China's rapid increase of inter-country airline services has just started.

Korea, whose airline network is highly connected with China, is urged to analyze the evolving status of its airline logistics from the overall viewpoint of the East Asian region. The evolving status of Korean airports is mostly arising from the rapid increase of China's air transport volumes and the growing importance of China's airports(Ha et al., 2005).

For example, until recently, Incheon airport had been operating as a transferring airport for the Chinese airlines departing for Europe and the U.S. However, Incheon airport has been losing its hub airport status because of developing direct flight lines from China to the U.S. and Europe.

Despite their importance, there is little academic research on the airport network in the Northeast Asian region mainly due to data availability. It is challenging to get a detailed inter-country air transport dataset. For this research, we collected flight schedules from more than 114 airports around the world. 
In this paper, focusing on inter-country airline network, the comparative logistics status of individual airports in East Asian countries will be examined. In Section 2, using the concept of centrality, descriptive features of the airline networks are described. Also group structures of the East Asian airports are introduced in this part. In Section 3, using the various notions of brokerage, specific roles of each airport are classified. In Section 4, using the notion of Structural Hole, the potential amelioration of network structure is analyzed. In Section 5, policy implications for airline networks are drawn from the Korean perspective.

\section{Centrality of Airports in Northeast Asia}

\subsection{Degree Centrality}

We gathered flight schedules from more than 100 airports, in the sense that these are the proxy variables for the inter-airport transport volume. Each data means the number of flight schedules during June 24 to June 30 in 2013. In addition, every link is weighted by their flight schedule number. The top $20 \%$ link can explain more than $57 \%$ of total flight dataset we gathered, so we focused on the $20 \%$ link to analyze the dataset. Also in the supposition that every flight has its round-trip schedule, we do not classify in and out links, that is to say, we ignore the direction of every link.

\section{Table 1.}

Top 5 airports by Degree and Betweenness Centrality

\begin{tabular}{c|c|c|c|c|c|c}
\hline \multirow{2}{*}{ Rank } & \multicolumn{2}{|c|}{ With domestic lines } & \multicolumn{2}{|c|}{ Without domestic lines } & \multicolumn{2}{|c}{$\begin{array}{r}\text { Flight lines only to and from } \\
\text { China }\end{array}$} \\
\cline { 2 - 7 } & DC & BC & DC & BC & DC & BC \\
\hline 1 & Beijing & Incheon & Incheon & Incheon & Beijing & Hong Kong \\
\hline 2 & Incheon & New York & Singapore & Paris & $\begin{array}{c}\text { Shanghai } \\
\text { /Pudong }\end{array}$ & Beijing \\
\hline 3 & $\begin{array}{c}\text { Shanghai } \\
\text { /Pudong }\end{array}$ & Beijing & Hong Kong & $\begin{array}{c}\text { Tokyo } \\
\text { Narita }\end{array}$ & Shenzhen & $\begin{array}{c}\text { Shanghai } \\
\text { /Hongqiao }\end{array}$ \\
\hline 4 & New York & $\begin{array}{c}\text { Tokyo } \\
\text { Narita }\end{array}$ & $\begin{array}{c}\text { Tokyo } \\
\text { Narita }\end{array}$ & New York & $\begin{array}{c}\text { Shanghai } \\
\text { /Hongqiao }\end{array}$ & Shenzhen \\
\hline 5 & Shenzhen & Hong Kong & Toronto & Singapore & Hong Kong & Xiamen \\
\hline
\end{tabular}


Degree Centrality and Betweenness Centrality have been widely used in the Social Network Analysis to explain a node's(actor's) influence or its relative importance within a complex network(Borgatti \& Li, 2009; Ducruet \& Lugo, 2013; Kim et al., 2011; Lee \& Wang, 2012). Degree Centrality is one of the most common measure of centrality network analysts focus on (Scott, 2000). It is calculated from the weighted links directly connected with a particular node. Therefore, each node has its values and the larger directed linked node, the higher Degree Centrality. It is recognized centrality index can represent the possibility of the local logistics hub where logistics quantity is gathered and re-distributed(Borgatti \& Li, 2009).

In our paper, Degree Centrality is calculated by the flight schedule numbers with other airports. In Figure 1, the airports of higher Degree Centrality are presented. Beijing Capitol Airport has the highest Degree Centrality, and Incheon, Shanghai Pudong, and Shenzhen airport have the second highest Degree Centrality(table 1).

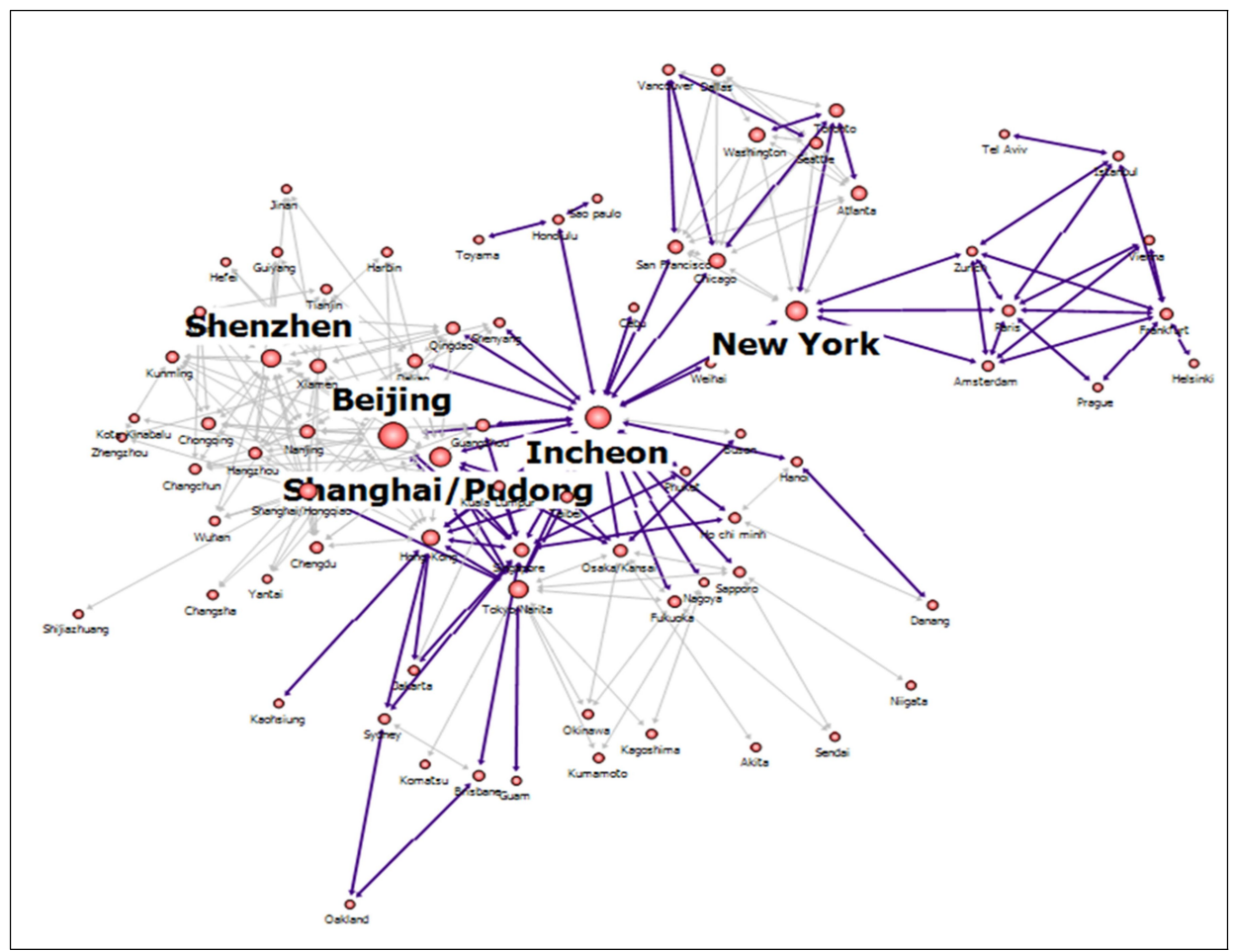

Figure 1.

Degree Centrality of airports in the East Asia

Notes : The bold blue lines represent international lines and the narrow gray lines represent domestic lines. Larger circles represent higher degree centrality in the network. Isolated nodes are excluded. 
Considering that Chinese airports have relatively large number of domestic lines, we calculated Degree Centrality excluding domestic lines of each airport. As shown in Figure 2, Incheon, Singapore, Hong Kong and Tokyo Narita have the highest Degree Centrality in order of size. Combined with the analysis based on Figure 1, the Degree Centrality of Chinese airports is inflated due to a large number of domestic lines.

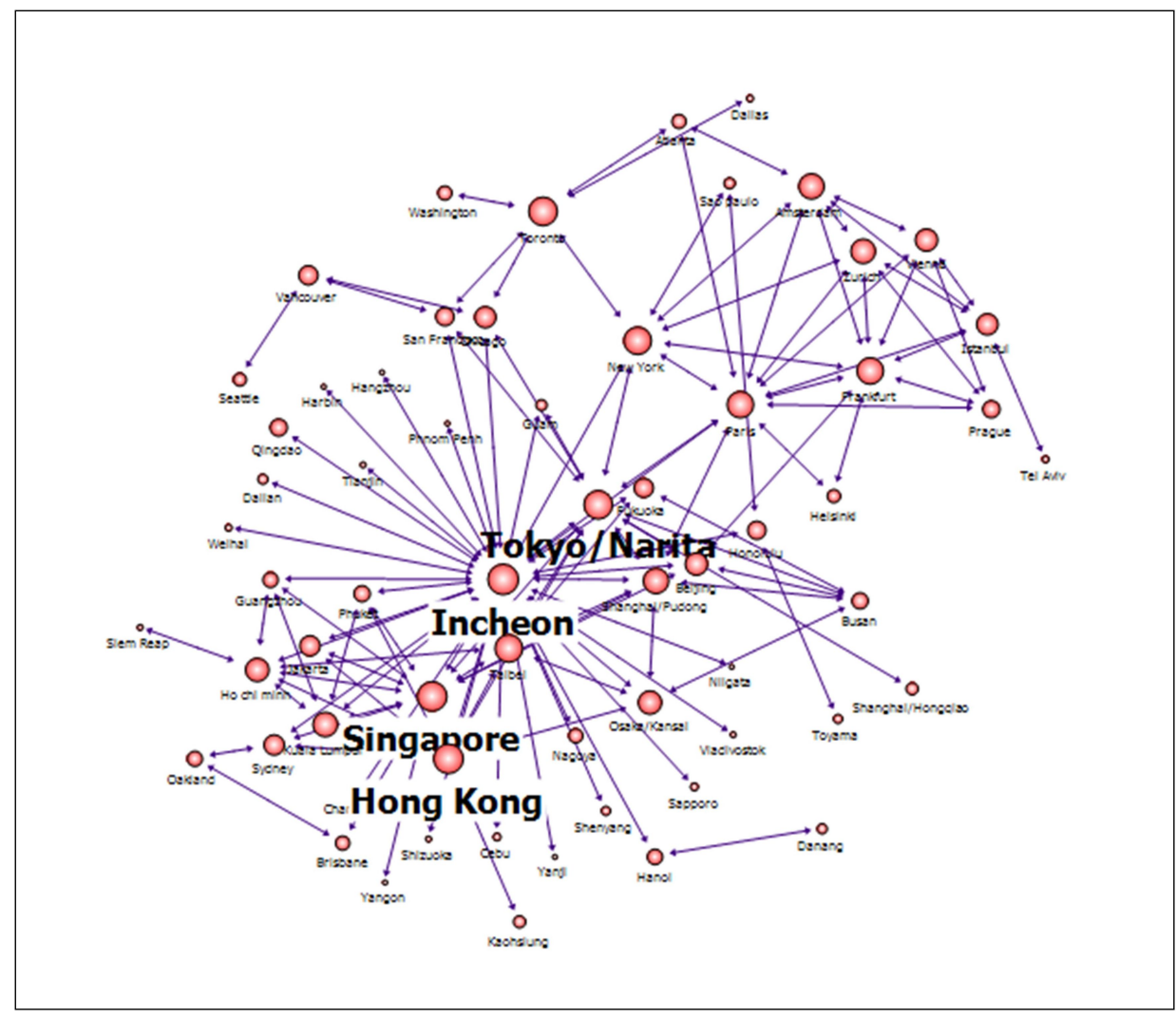

Figure 2.

Degree Centrality of airports without domestic lines

\subsection{Betweenness Centrality}

Betweenness Centrality is defined by the statistical possibilities that a node A is located in the shortest path between node B and node C. So, it has quite a critical role in airline network and its indicator of airport's intermediacy representing likelihood as a potential hub(da Rocha, 2009). In general, the more central the node, the larger the number 
of shortest paths passing through this node(Barthélemy, 2011: 15). The Betweenness Centrality of node $i$ is calculated by $\frac{\sum_{j<k} g_{j k}\left(n_{i}\right) / g_{j k}}{(g-1)(g-2) / 2}$. In this equation, $(g-1)(g-2) / 2$ is the number of node pairs that does not pass node $\mathrm{i}, \sum_{j<k} g_{j k}\left(n_{i}\right) / g_{j k}$ is the probability the node $i$ is located in the shortest path between node $j$ and node $k$.

The hub airports based on the Betweenness Centrality are Incheon, Beijing, Tokyo/Narita, Hong Kong. Among these airports in Northeast Asia, Incheon has the highest Betweenness Centrality. However, considering only the flight lines to and from China's airports, Hong Kong has the highest Betweenness Centrality, which implies that Hong Kong is the hub airport of China's international air transportation.

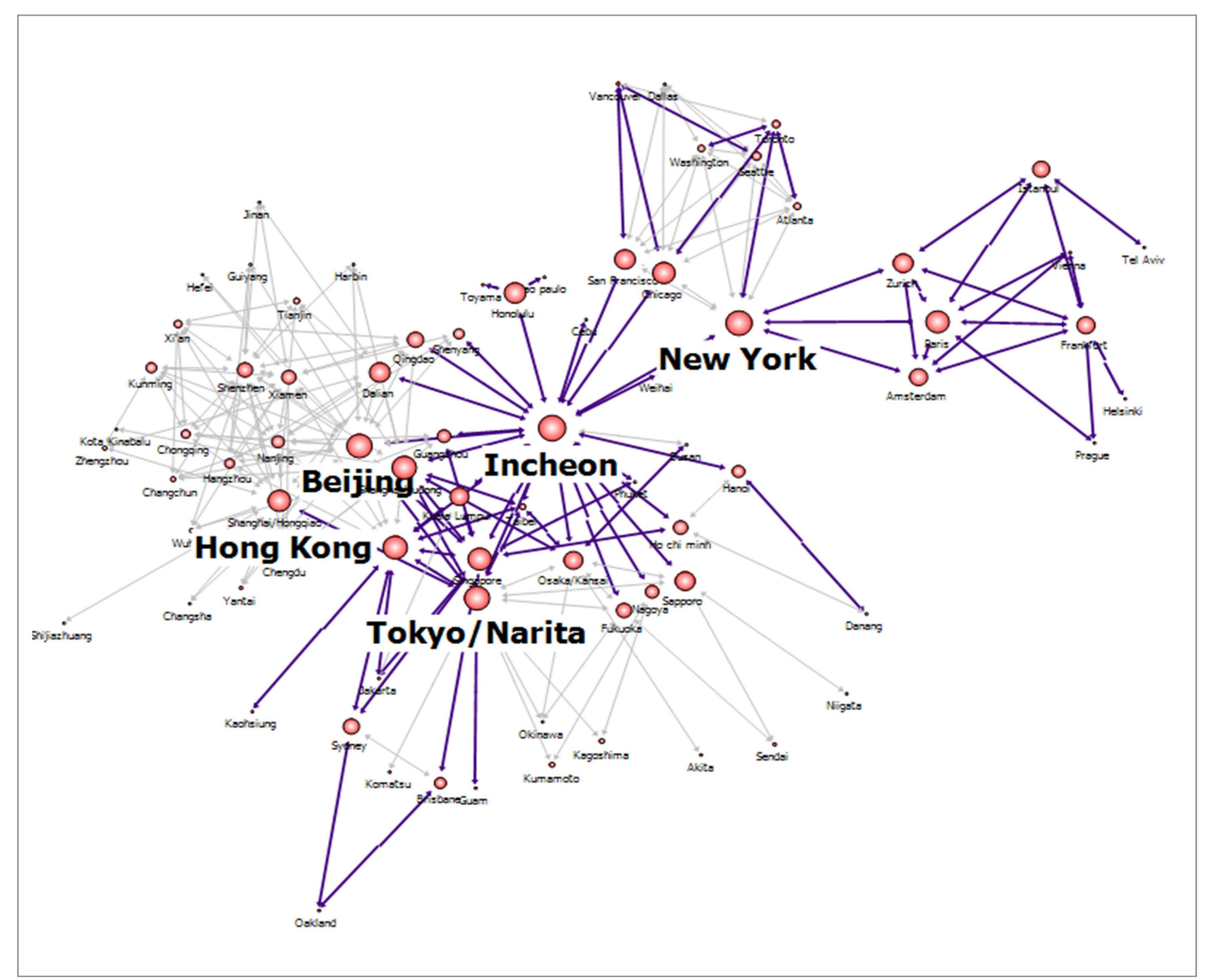

Figure 3.

Betweenness Centrality of airports

Notes : The bold blue lines represent international lines and the narrow gray lines represent domestic lines. The size of nodes denotes the level of Betweenness Centrality. 


\subsection{Community Modularity}

Community Modularity captures the group structures of the network. Based on the Community Modularity, every node in the network is classified into a specific group where in-group links are more than out-of-group links. As shown in Figure 4, Shanghai/Pudong, for example, has more links with Beijing (in-group links) than with Hongkong(out-of-group links). According to Guimera et al.(2005), communities in airline network are important to analyze which ones are less connected and find the ways to minimize that constraints.

Through the Community Modularity, airports in the East Asia are classified into three separate groups by their linkage structure. The first group is composed of China's airports. The second group is Korean and Japanese airports. The third group is composed of South Asian airports mainly Hong Kong and Singapore.

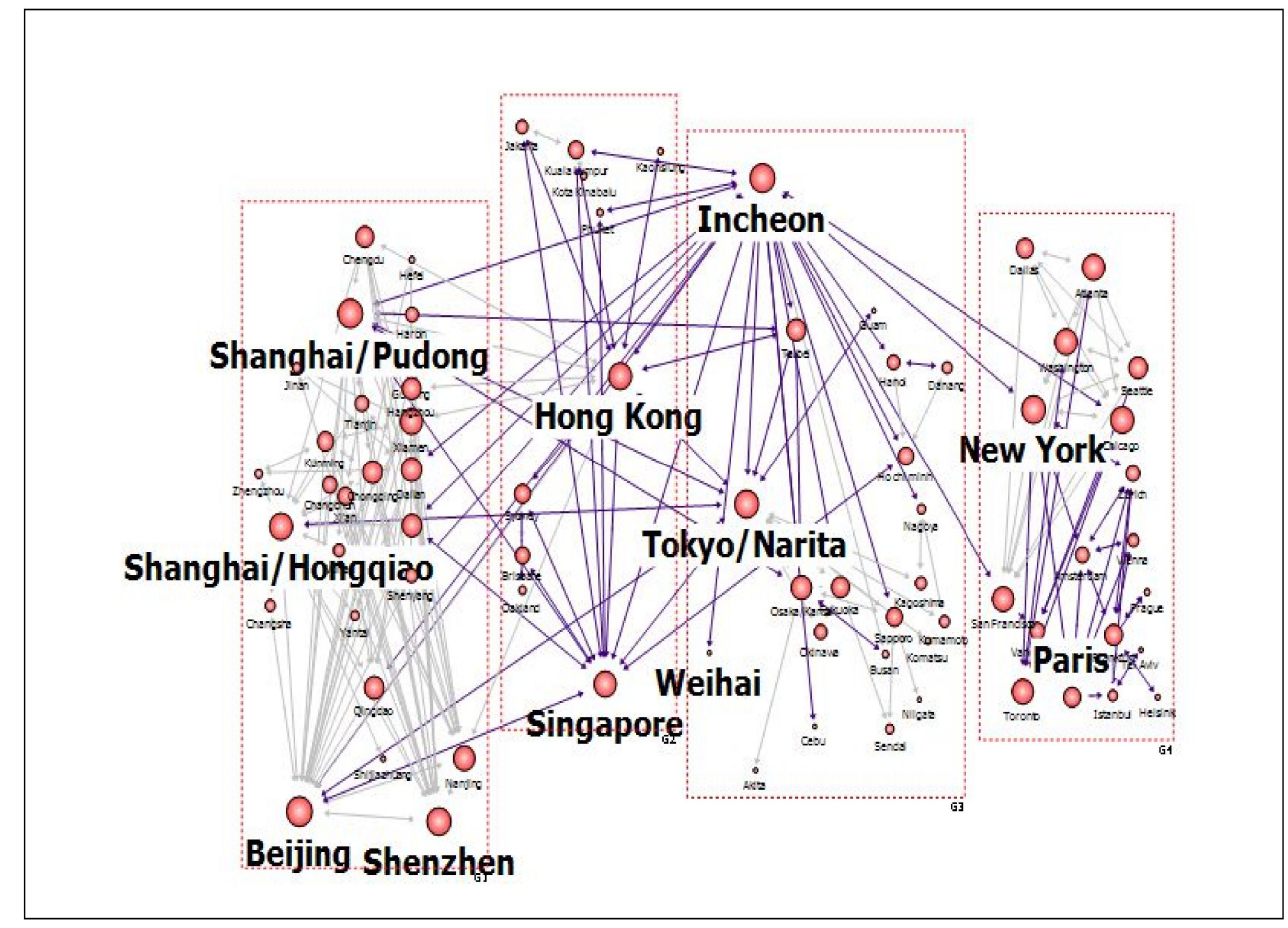

Figure 4.

Community Modularity of airports 


\section{Brokerage Role in Northeast Asia}

Gould and Fernandez(1989) proposed a set of measures for brokering roles in the network analyses. According to Gould and Fernandez (1989), nodes can be classified with their brokerage types, such as coordinator, gatekeeper, liaison, itinerant broker(consultant) and representative. A 'coordinator' means that they intermediate relations between members of their own group. A 'gatekeeper' is a node whose role is focusing on accepting from a different group and releasing the links in contact with its own group. And finally, a 'liaison' is a node which brokers relations belonging to different groups(Vicente et al., 2011:1073).

In our analyses, the group is automatically defined by Modularity group structure. The role of coordinator is remarkably high in China's airports, such as Beijing, Shenzhen, Shanghai/Hongqiao and Shanghai/Pudong, which means that these are the hub airports of China's domestic airline network. Tokyo/Narita, Beijing, Hong Kong, and Incheon play a strong role of gatekeeper meaning that these are the gate airports which distribute to/from the international and domestic airline networks. Most interestingly, Incheon has remarkably high scores as a liaison. In this sense, Incheon is a focal hub airport which mainly distributes international airlines.

\section{Table 2.}

Brokerage roles of the airline network in Northeast Asia

\begin{tabular}{c|c|c|c}
\hline Airport & Coordinator & Gatekeeper & Liaison \\
\hline Incheon & 0 & 23 & 434 \\
\hline Singapore & 0 & 0 & 88 \\
\hline Hong Kong & 12 & 41 & 34 \\
\hline Tokyo/Narita & 34 & 51 & 24 \\
\hline Beijing & 254 & 45 & 0 \\
\hline Shenzhen & 184 & 0 & 4 \\
\hline Shanghai/Pudong & 76 & 46 & 0 \\
\hline Shanghai/Hongqiao & 142 & 13 & \\
\hline
\end{tabular}




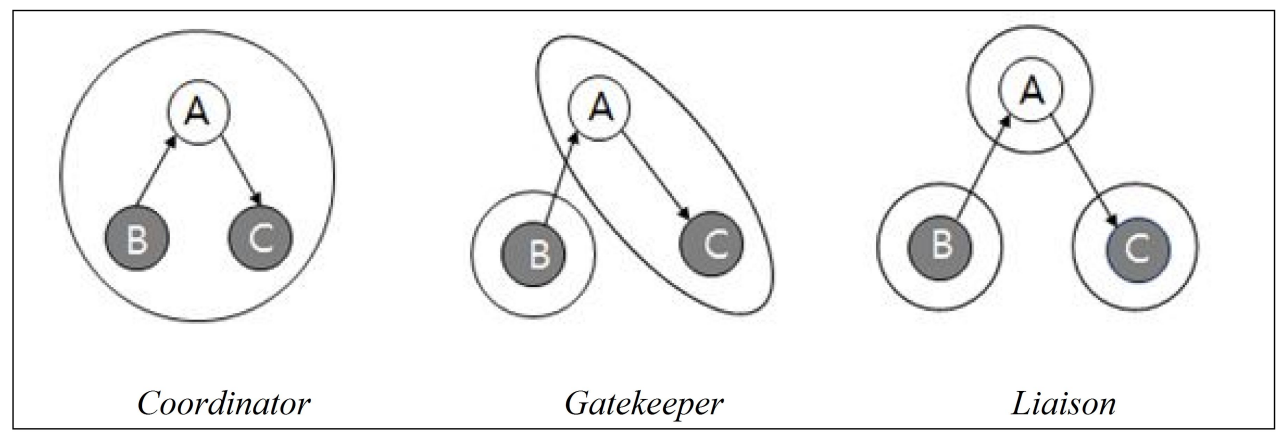

Figure 5.

Types of brokerage roles

Source: Kirkels \& Duysters, 2010, p. 377.

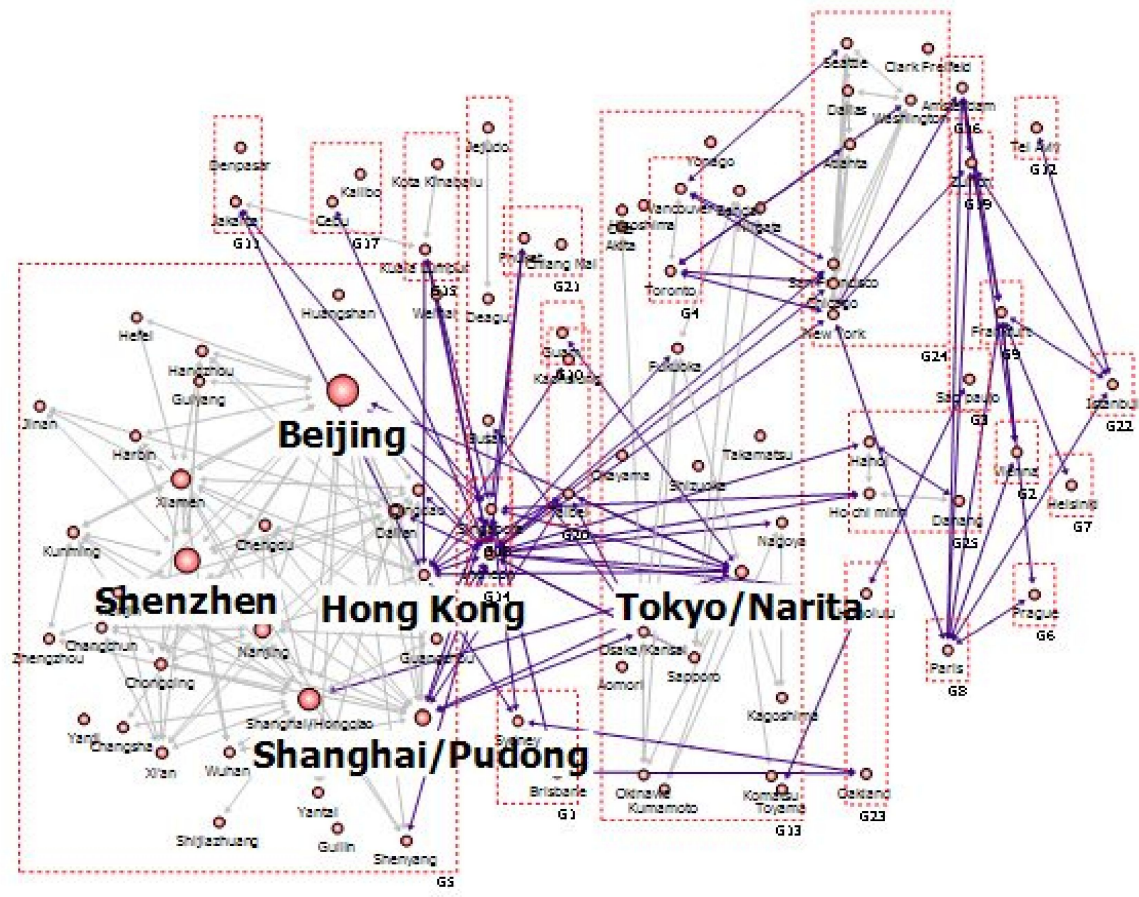

Figure 6.

Coordinator of airline network in Northeast Asia 


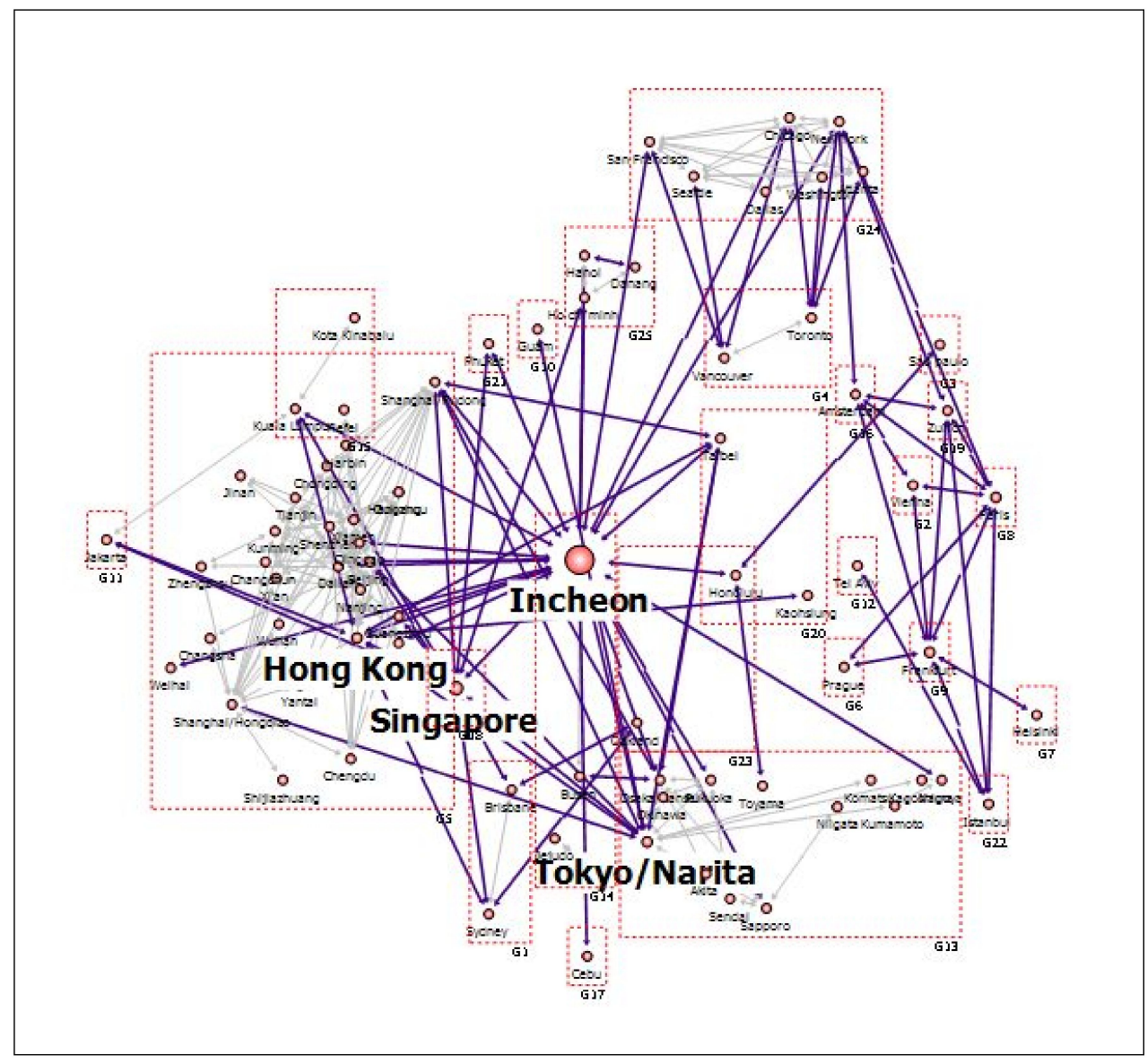

Figure 7.

Liaison of airline network in Northeast Asia

Taking into account the growing importance of China's airports, we analyze the brokerage roles of Northeast Asian airports including only to/from China airports. In this analysis, Hong Kong is the highest in its liaison role, which implies that Hong Kong is a potential competitor to Incheon as China's airline network is reinforced. Among China's domestic airline network, Beijing, Shenzhen, Xiamen, Nanjing and Shanghai/Pudong are coordinator airports, that is to say, these airports are hub airports for China's domestic airlines. 
Table 3.

Brokerage roles in the airline network of China

\begin{tabular}{c|c|c|c}
\hline Airport & Coordinator & Gatekeeper & Liaison \\
\hline Hong Kong & 8 & 36 & 54 \\
\hline Beijing & 260 & 29 & 0 \\
\hline Nanjing & 90 & 0 & 2 \\
\hline Shanghai/Pudong & 62 & 14 & 0 \\
\hline Shenzhen & 200 & 0 & 0 \\
\hline Xiamen & 110 & 9 & 0 \\
\hline Shanghai/Hongqiao & 72 & 0 & 2 \\
\hline
\end{tabular}

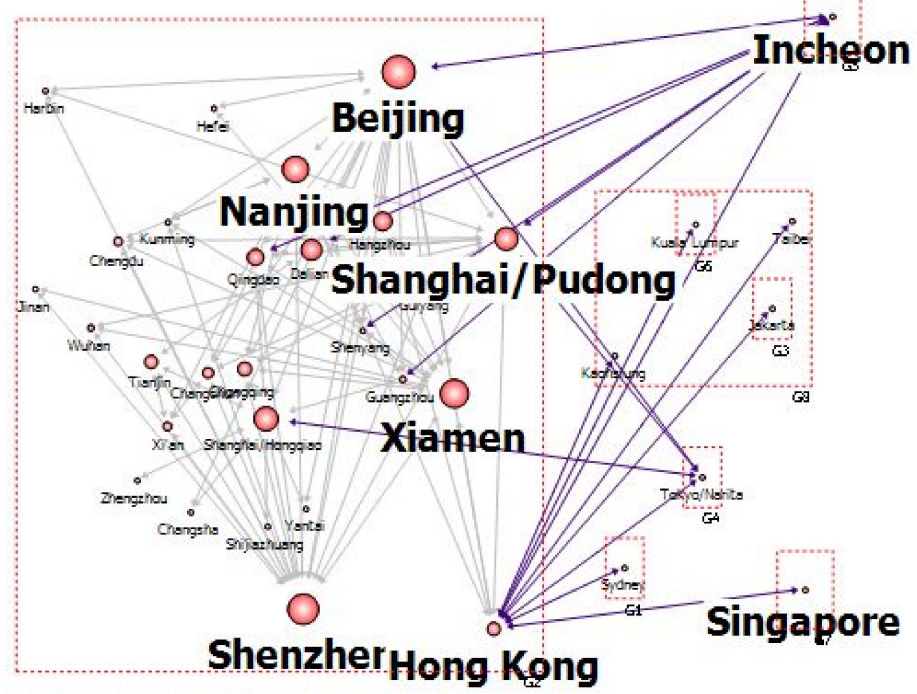

Figure 8.

Coordinator of airline network in China 


\section{Structural Hole}

The Structural Hole is a tool used to investigate potential hub nodes by the notion that non-redundant contacts are connected by a structural hole(Burt, 1992) or unconnected space in a network can be exploited as a result of brokering connections(Gudmundsson \& Lechner, 2006). In addition, Structural Holes refer to the social gap of information, capital and resources, etc. Having a Structural Hole benefits in several ways: controlling goods and services flows and creating innovative idea or behavior by acting as bridges and buffers(Tracey \& Clark, 2003).

Moreover, in line with the work of Burt(2001), Gudmundsson and Lechner(2006) argue that participation in multilateral airline alliances can be effective by bridging 'structural holes'. According to them, the firm's competitive capabilities in airline network depend on occupying structural holes. And they suggest that multilateral airline alliances can be expected to maintain structural holes by adding partners that are beneficial and removing partners with many redundant ties.

In the structural hole analysis, lower constraints of a node represent less redundant node, which imply higher possibilities of structural hole. In Northeast Asian airports, Incheon has the lowest constraint. It implies that Incheon has potentially higher possibilities to create new links among Northeast Asian airline networks.

\section{Table 4.}

'Structural Holes Measures' of airports in Northeast Asia

\begin{tabular}{c|c|c|c|c|c}
\hline \multicolumn{2}{c|}{ Airport } & Efficiency & Effective Size & $\begin{array}{l}\text { Aggregate } \\
\text { Constraint }\end{array}$ & Hierarchy \\
\hline 1 & Incheon & 0.918670 & 22.966754 & 0.114236 & 0.196436 \\
\hline 2 & Tokyo/Narita & 0.869033 & 13.035491 & 0.153905 & 0.191961 \\
\hline 3 & Beijing & 0.851150 & 18.725291 & 0.157287 & 0.175470 \\
\hline 4 & Shanghai/Pudong & 0.814134 & 13.026148 & 0.186394 & 0.245291 \\
\hline 5 & Hong Kong & 0.846914 & 11.856799 & 0.195624 & 0.219697 \\
\hline 6 & Singapore & 0.862865 & 10.354376 & 0.209516 & 0.144425 \\
\hline
\end{tabular}

Note : The smaller network constraint index, the more structural holes. 


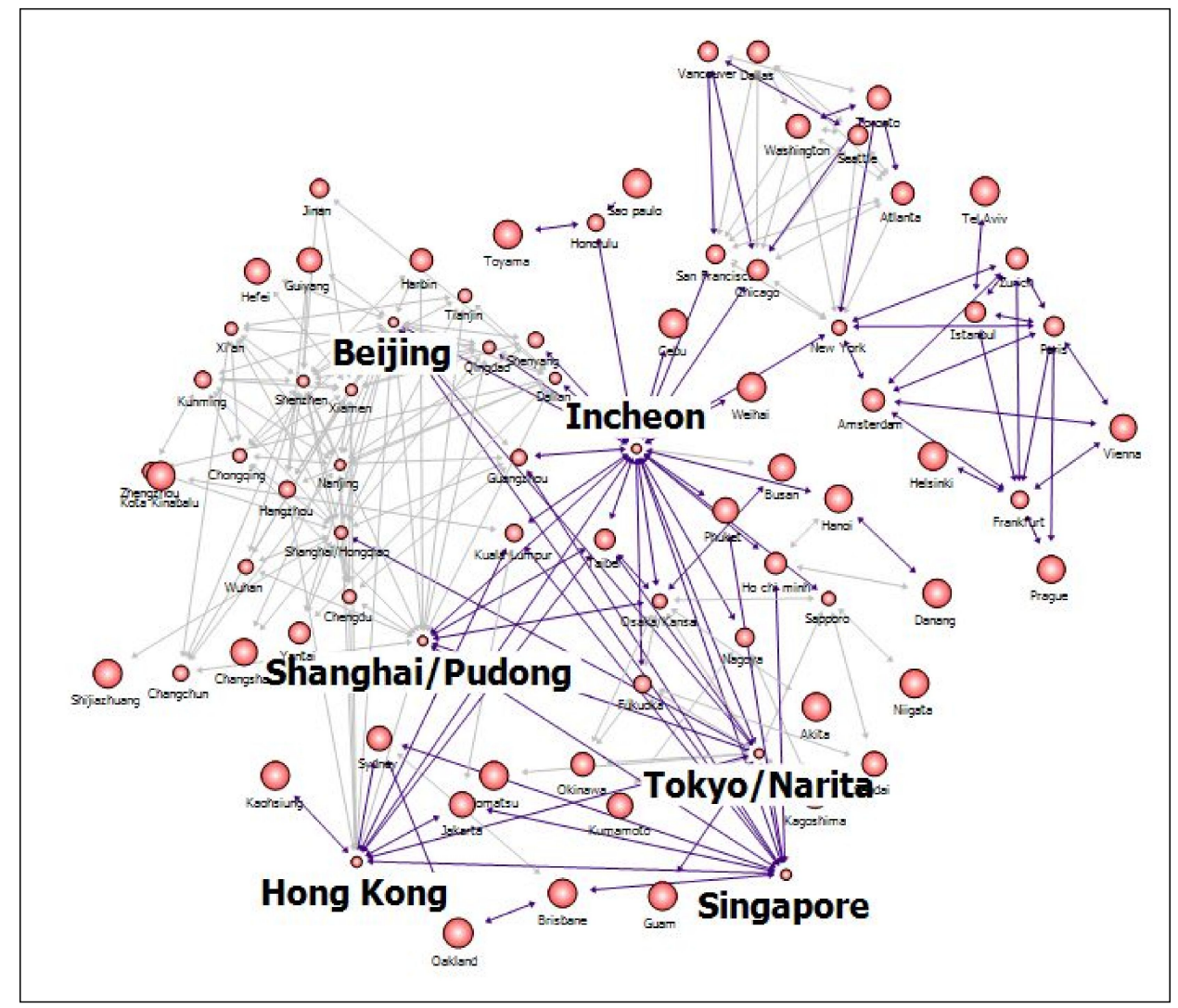

Figure 9.

Airline network with structural holes in Northeast Asia

Note: This analysis is based on 'Aggregate Constraint'.

Table 5.

'Structural Holes Measures' of airports in China

\begin{tabular}{c|c|c|c|c|c}
\hline & Airport & Efficiency & Effective Size & $\begin{array}{c}\text { Aggregate } \\
\text { Constraint }\end{array}$ & Hierarchy \\
\hline 1 & Hong Kong & 0.915788 & 11.905248 & 0.159973 & 0.263085 \\
\hline 2 & Beijing & 0.847184 & 17.790867 & 0.173506 & 0.182990 \\
\hline 3 & Nanjing & 0.806646 & 9.679746 & 0.221621 & 0.186891 \\
\hline 4 & Shanghai/Pudong & 0.803065 & 9.636785 & 0.229561 & 0.236939 \\
\hline 5 & Shenzhen & 0.788653 & 13.407093 & 0.231177 & 0.266963 \\
\hline 6 & Xiamen & 0.812193 & 10.558504 & 0.242245 & 0.256085 \\
\hline
\end{tabular}

Note : The smaller network constraint index, the more structural holes. 


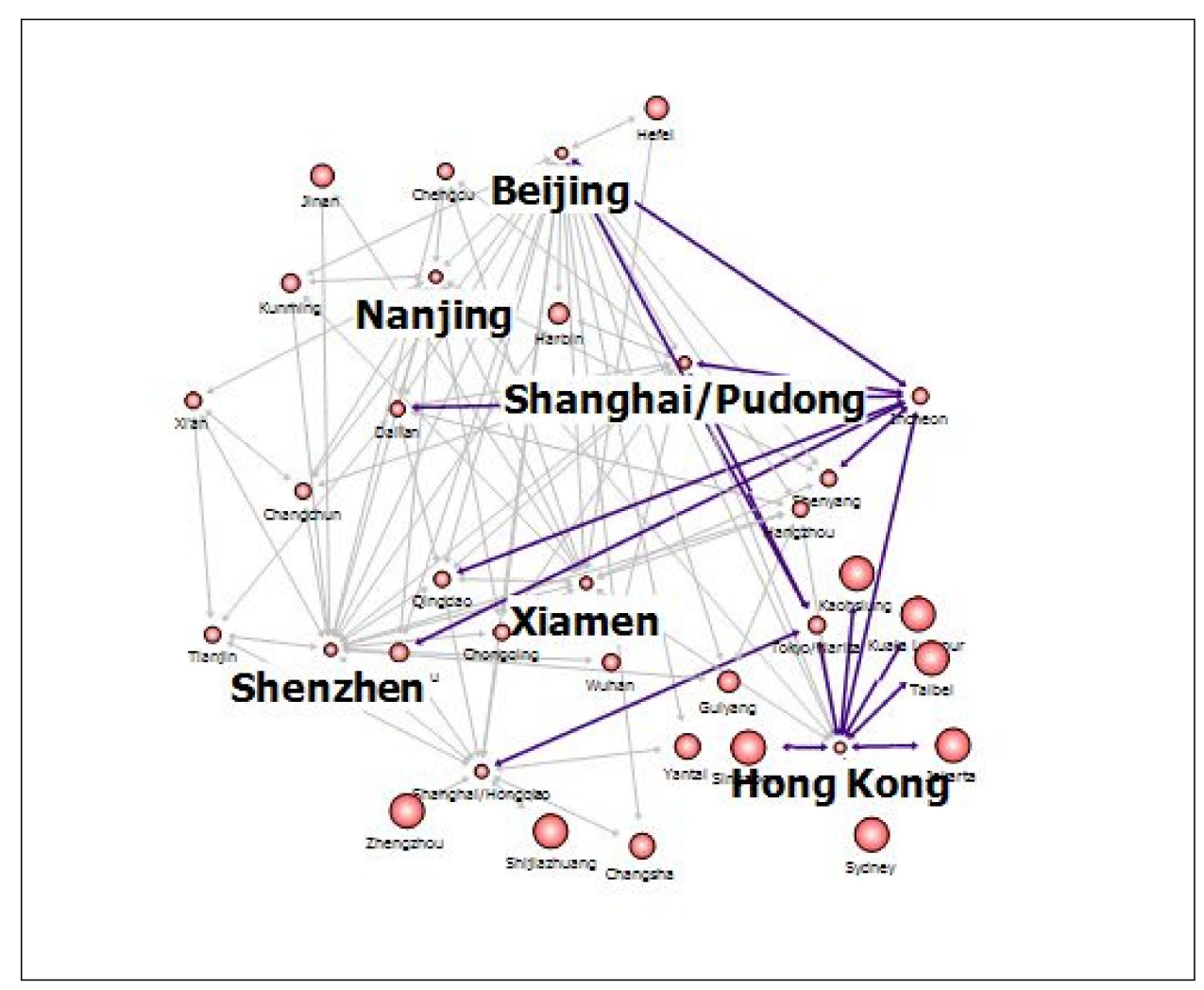

Figure 10.

Airline network with structural holes in China

Note: This analysis is based on 'Aggregate Constraint'

\section{Policy Implications and Concluding Remarks}

Using Social Network Analysis (SNA), this paper examines the inter-country airline logistics relationships in East Asia. Based on the flight schedule gathered by authors, the overall features of airline logistics structure and the specific roles of each airport could be more clearly examined.

This paper suggests several implications: Beijing has the highest Degree Centrality, but excluding the domestic lines, Incheon has the highest Degree Centrality. It implies that a relatively high Centrality of logistics for China's airports is due to the greater number of domestic lines. The focal hub status of Incheon airport is also supported by the fact that Incheon contains the highest Betweenness Centrality. 
Secondly, the group structure, analyzed by the Community Modularity, reveals three larger groups in the East Asian region: Korea-Japan, China, and Southern Asia which includes Hong Kong, Singapore and ASEAN countries. This means that the major airports in each group such as Beijing and Shanghai, Incheon and Tokyo, Hong Kong and Singapore, will be potential rivals in the regional airline logistics relationship.

Thirdly, evaluated by the types of brokerage role, Incheon has a remarkably strong role as a liaison, which means Incheon airport functions as a transfer hub between two different regions outside of Korea. However, considering only the to/from China airline links, Hong Kong has the highest score as a liaison. These conflicting results imply that as China's airline transportation continuously increases, Hong Kong will become a strong rival to Incheon.

Lastly, in the the analysis of Structural Hole which functions the broker and acts as a hub by linking unconnected airports, Incheon has the highest possibilities as a hub airport. However, only considering to/from China airlines, Hong Kong would dominate Incheon.

For Korean airline policy makers, these analyses could introduce two policy implications, one is to reinforce the liaison role of Incheon airport which means the inter-region hub airport. To implement this policy, Incheon needs to be more globally competitive and effective. The second policy would be to focus on China by pursuing a strategy like that of Hong Kong which plays the role of liaison in the inter-connections with China's airports. 


\section{References}

Barthélemy, M. (2011) “Spatial Networks,” Physics Reports, 499, 1-101.

Borgatti, S. P., Li, X. (2009) "On Social Network Analysis in A Supply Chain Context," Journal of Supply Chain Management, 45(2), 5-22.

Burt, R. S. (1992) Structural Holes: The Social Structure of Competition. Cambridge MA: Harvard University Press.

Burt, R. S. (2001) Structural Holes versus Network Closure as Social Capital, in Lin, N., Cook, K. S., Burt, R. S.(Eds.), Social Capital: Theory and Research, New York: Aldine de Gruyter, 31-56.

da Rocha, L. E. C. (2009) "Structural Evolution of Brazilian Airport Network," Journal of Statistical Mechanics: Theory and Experiment, 4, P04020.

Ducruet, C., Lugo, I. (2013) Structure and Dynamics of Transportation Networks: Models, Methods and Applications, in Rodrigue, J-P., Notteboom, T. E. \& Shaw, J.(Eds.), The SAGE Handbook of Transport Studies, London: SAGE Publications, 347-364.

Gould, R. V., Fernandez, R. M. (1989) "Structures of Mediation: A Formal Approach to Brokerage in Transaction Networks," Sociological Methodology, 19, 89-126.

Gudmundsson, S. V., Lechner, C. (2006) "Multilateral Airline Alliances: Balancing Strategic Constraints and Opportunities," Journal of Air Transport Management, 12, 153-158.

Guimera, R., Mossa, S., Turtschi, A. \& Amaral, L. A. N. (2005) "The Worldwide Air Transportation Network: Anomalous Centrality, Community Structure, and Cities' Global Roles," Proceedings of the National Academy of Sciences, 102(22), 7794-7799.

Ha, H-K., Kim, T. S. \& Kim, Y. J. (2005) "Analysis of the Logistics Patterns of Korea's Free Economic Zones in Northeast Asia and the Implications" Journal of international logistics and trade, 3(2), 73-92. 
Kim, Y., Choi, T. Y., Yan, T. \& Dooley, K. (2011) "Structural Investigation of Supply networks: A social Network Analysis Approach," Journal of Operational Management, 29, 194-211.

Kirkels, Y., Duysters, G. (2010) "Brokerage in SME Networks," Research Policy, 39(3), 375-385.

Lee, J. Y., Wang, S. (2012) "Inter-Provincial Railroad Network in China," Journal of international logistics and trade, 10(2), 61-75.

Scott, J. (2000) Social network analysis: A handbook, London: Sage Publications.

Tracey, P., Clark, G. L. (2003) "Alliances, Networks and Competitive Strategy: Rethinking Clusters of Innovation," Growth and Change, 34, 1-16.

Vicente, J., Balland, P. A. \& Brossard, O. (2011) "Getting into Networks and Clusters: Evidence from the Midi-Pyrenean Global Navigation Satellite Systems(GNSS) Collaboration Network," Regional Studies, 45 (8), 1059-1078.

Wang, J., Mo, H., Wang, F. \& Jin, F. (2011) "Exploring the Network Structure and Nodal Centrality of China's Air Transport Network: A Complex Network Approach," Journal of Transport Geography, 19(4), 712-721. 